\title{
Article \\ Investigation of Oxy-Fuel Combustion through Reactor Network and Residence Time Data
}

\author{
Maria Angela Agizza ${ }^{1}$ (D), Ghobad Bagheri ${ }^{2}$ (D), Sebastian Bürkle ${ }^{1}$, Tiziano Faravelli ${ }^{2}$, Steven Wagner ${ }^{1}$ (D) \\ and Andreas Dreizler ${ }^{1, *}$ \\ 1 Fachgebiet Reaktive Strömungen und Messtechnik, Technische Universität Darmstadt, \\ 64287 Darmstadt, Germany; maagizza@gmail.com (M.A.A.); sebastian.buerkle@gmail.com (S.B.); \\ wagner@rsm.tu-darmstadt.de (S.W.) \\ 2 Dipartimento di Chimica, Materiali e Ingegneria Chimica, Politecnico di Milano, 20133 Milano, Italy; \\ Ghobad.Bagheri@gmail.com (G.B.); tiziano.faravelli@polimi.it (T.F.) \\ * Correspondence: dreizler@rsm.tu-darmstadt.de
}

Citation: Agizza, M.A.; Bagheri, G.; Bürkle, S.; Faravelli, T.; Wagner, S.; Dreizler, A. Investigation of Oxy-Fuel Combustion through Reactor Network and Residence Time Data. Energies 2022, 15, 252. https:// doi.org/10.3390/en15010252

Academic Editors: Osvalda Senneca and Martin Schiemann

Received: 2 November 2021

Accepted: 24 December 2021

Published: 30 December 2021

Publisher's Note: MDPI stays neutral with regard to jurisdictional claims in published maps and institutional affiliations.

Copyright: (C) 2021 by the authors. Licensee MDPI, Basel, Switzerland. This article is an open access article distributed under the terms and conditions of the Creative Commons Attribution (CC BY) license (https:// creativecommons.org/licenses/by/ $4.0 /)$.

\begin{abstract}
Oxy-fuel combustion is a promising strategy to minimize the environmental impact of combustion-based energy conversion. Simple and flexible tools are required to facilitate the successful integration of such strategies at the industrial level. This study couples measured residence time distribution with chemical reactor network analysis in a close-to-reality combustor. This provides detailed knowledge about the various mixing and reactive characteristics arising from the use of the two different oxidizing streams.
\end{abstract}

Keywords: oxy-fuel combustion; chemical reactor network (CRN); residence time distribution (RTD); carbon capture and storage (CCS)

\section{Introduction}

The combustion of fossil fuels plays an essential role in power generation, owing to its high power density and flexibility. While its application remains prominent, it is vital to minimize its negative environmental impacts [1-3]. To this end, new combustion processes to simultaneously improve fuel consumption and decrease pollutant emissions as well as smart post-treatment methods must be developed [4]. Carbon Capture and Storage (CCS) is identified as a key strategy to mitigate combustion-induced climate change [1,2,5-7]. It allows for exploitation of the benefits of carbon-based energy conversion with minimal changes and high retrofitting possibilities. Oxy-fuel combustion is a promising technology that significantly enables CCS by leading to an exhaust gas mainly composed of carbon dioxide $\left(\mathrm{CO}_{2}\right)$ and water vapor $[8,9]$. Such a concept, though exhibiting undeniable advantages, must be carefully studied in order to fully understand the hidden aspects required for successful integration at the industrial level.

A compelling investigation demands a strong synergy between experiments and modelling, ideally resulting in efficient and flexible analysis tools that quickly estimate the optimal operation parameters. Residence Time Distribution (RTD) measurement is widely employed in chemical industries to analyze the ongoing process and evaluate reactor performance [10-12]. Besides providing a significant insight into the mixing and reactivity of the flow, RTD data further improves the design and dimensioning of a Chemical Reactor Network (CRN) of the system under investigation [13,14]. A CRN employs a properly designed arrangement of ideal flow reactors to obtain a simplified model for the combustor flow field. Identifying macromixing zones inside the considered facility makes it easier to pinpoint the zonal behaviors where optimization effort can be an option.

Furthermore, such simplification enables implementation of detailed kinetic mechanisms where a complete description of the combustion process can be acquired. This unique advantage makes CRN modelling the preferred alternative compared to Computational 
Fluid Dynamics (CFD). While a valuable tool, CFD's computational costs are high, especially when incorporating detailed kinetic mechanisms. Nevertheless, its essential features of increasing combustion efficiency and lowering the pollutant emissions of combustionbased devices are determined by the complex interaction between turbulence and chemical reactions $[15,16]$, requiring the inclusion of complex kinetics.

The schematization of a combustion chamber utilizing a network of interconnected ideal flow reactors has been successfully achieved in the past [17-22]. The earliest works [17-19] designed a CRN by identifying the mixing characteristics and modelling them accordingly with ideal flow reactors. The authors of [23] enriched this approach, proposing a strategy to schematize the diffusive fluxes necessary to properly describe a diffusion flame despite modeling the system with ideal flow reactors, which expect a homogeneous feed. These early methodologies have been further employed in more recent works [20-22] which comprise the refinement for diffusion flames based on the work in [23]. Timón et al. followed the example set by [17] in their work [24] comparing standard gas turbine combustion chambers and oxyfuel combustion for the Semi-Closed Oxyfuel Combustion Combined Cycle (SCOC-CC). The system was rigorously modeled from the technical point of view, and highlighted the different technical aspects to consider when designing oxyfuel combustion systems. In addition, CRNs are sometimes coupled with CFD modelling to facilitate the design of the network model [16,25-27]. For this reason, an automated hybrid CFD-CRN approach has been developed and implemented by [28-31].

Despite the proven effectiveness of an automated CFD-CRN approach, more straightforward approaches are often preferred for dealing with industrial applications. The reason lies in the possibility of better identifying the impact of operating parameters on coarser mixing zones associated with the reactor's mixing properties. Reactor network studies based on RTD perfectly fit this scenario because RTD yields the mixing characteristics of the system, which must be reproduced to describe a reactive flow. Beér and Lee and Van Der Lans et al. [32,33] coupled RTD and CRN modelling to analyze the effect of the swirl number in a combustion furnace, whereas in the works [34-36], technical issues related to combustor design are uncovered and addressed through RTD-CRN modelling. Such an investigation strategy is also applied in $[37,38]$ to clarify the effect of steam dilution on the flow field, while RTD-CRNs are usually kept simple and have not yet incorporated chemical kinetics.

The objective of the present study is to exploit the RTD-CRN approach in order to gain detailed knowledge about the key controlling parameters of the combustion process stemming from the substitution of $\mathrm{N}_{2}$ with $\mathrm{CO}_{2}$ in oxy-fuel combustion. Comparing the two oxidizing atmospheres provides the insight needed to properly retrofit existing operating power plants while retaining the provided performance. To further this aim by investigating cold flow and reactive conditions, a CRN of a down-scaled version of a furnace is designed here, utilizing previous RTD experiments carried out on the test rig. For the reactive case, kinetic results obtained from the network are therefore compared with the experimental data on pollutant emissions. The developed model enables a better understanding of the various mixing and reactive parameters inside the combustor for both air and oxy-fuel flames.

\section{Materials and Methods}

The Residence Time Distribution (RTD) is the probability of how long fluid elements remain inside a continuous process. The residence time of the species inside a reactive environment is a crucial factor influencing the complete conversion of the fuel (thus fuel efficiency) and the potential formation of harmful pollutants. While dealing with continuous and turbulent flow systems such as those of interest in practical combustion, fluid elements that entered the reactor simultaneously will not leave it at the same time. RTD measurements are achieved by injecting an inert tracer using a known input function and recording its concentration at the exit over time, $C(t)$ [39]. Employing a pulse input, RTD (mathematically referred to as $E(t))$ is directly retrievable through Equation (1) [11]. Once 
the distribution is known, the moments of the distribution can be calculated. Equations (2) and (3) show the most common moments of the RTD. The mean residence time, $\tau^{m}$ in Equation (2), indicates the average time pockets of fluid spend inside the system, while the variance of the distribution, $\left(\sigma^{2}\right)$ in Equation (3), gives information about its spread. In ideal cases, $\tau^{m}$ equals the time-space $\tau$ in Equation (4). Figure 1 shows the RTDs of the ideal flow reactors, the Continuous Stirred Tank Reactor (CSTR) and the Plug Flow Reactor (PFR), easily obtained by virtue of the underlying hypothesis behind these two basic models [11]. The ideal flow reactors represent the two extremes of mixing possibilities: for the CSTR, perfect and instantaneous mixing of all the entering streams is assumed, whereas for PFR, piston flow in the streamwise direction and ideal mixing in the generic cross-section along the flow axis are assumed [11].

$$
\begin{gathered}
E(t)=C(t) / \int_{0}^{+\infty} C(t) d t,[1 / \mathrm{s}] \\
\tau^{m}=\int_{0}^{+\infty} t E(t) d t,[\mathrm{~s}] \\
\sigma^{2}=\int_{0}^{+\infty}(t-\tau)^{2} E(t) d t,\left[\mathrm{~s}^{2}\right] \\
\tau=V / \dot{v},[\mathrm{~s}] \\
V=\text { reactor volume, }\left[\mathrm{m}^{3}\right] \\
\dot{v}=\text { volumetric flow rate, }\left[\mathrm{m}^{3} / \mathrm{s}\right]
\end{gathered}
$$

(a)
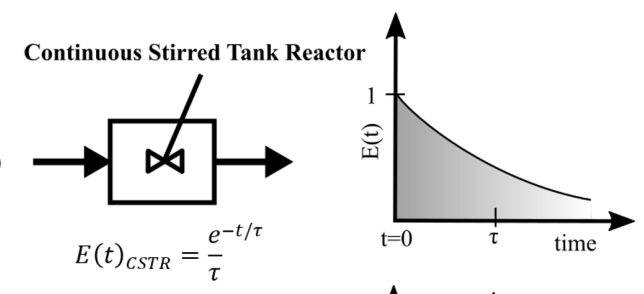

Plug Flow Reactor

(b)

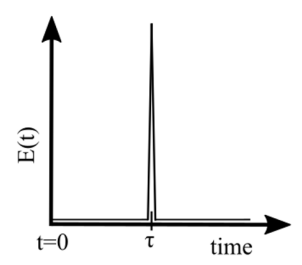

Figure 1. Ideal flow reactors and their RTDs. (a) CSTR; (b) PFR.

The flow behavior of real reactive systems lies between these two reactors, exhibiting complex residence time distributions for which mathematical treatment and understanding are not straightforward. For this reason, an actual reactor was schematized through an arrangement of ideal flow reactors with well-known RTD shapes. Such reactors must be arranged so that the RTD of the network matches the experimental RTD of the real system. Therefore, two macro-steps were identified to apply this investigation strategy:

- Determination of the reactor network structure, meaning the amount and type of reactors and their interconnections with mixing or splitting streams.

- Determination of the selected unknown variables. The most common are the volume of the reactors and the splitting ratio for each designed splitting stream, thus uniquely defining the processed flow rate and the residence times in the reactors. For nonisothermal processes, the final process temperature must also be set at this stage.

To design a suitable arrangement, flow visualization data can aid in the interpretation of RTD in terms of main flow structures. Useful data range from Particle Image Velocimetry (PIV) measurements for flow field investigation to CFD-computed streamlines. Unlike the cases reported in the literature [16,25-27], where the reactors' volumes and processed flow rates were directly calculated from CFD, in this case computed streamlines (where available) 
only serve to identify the major mixing zones and their interaction. Then, a PFR is chosen if a prevailing flow direction is present; otherwise, a CSTR is associated with the recirculation zone [40]. Once an arrangement is designed and the values of selected unknown variables must be determined, the CRN is treated as an optimization problem [41-43]: the mathematical model of the tracer propagation must be written in terms of the chosen variables, which are determined by fitting the model response to the experimental response. In this work, the mathematical model is solved by transforming it into the Laplace domain [44], and the routine implemented in MATLAB $^{\circledR} /$ Simulink $^{\circledR}$ (Natick, MA, USA) [45]. Based on these principles, the CRN shown in this work was designed following a stepwise approach starting from elementary arrangements [32,46,47]. Complexities were gradually added for implementing more features of the flow field. This approach allowed for reducing the number of unknown variables to be determined through the optimization, according to the following reasoning. Although flow visualization data support a first estimation of zone volume, the coordinates at which a certain zone can be located are not unambiguously demarcated. Therefore, the available experimental evidence has been exploited by designing coarse CRN, starting from 2-3 reactors and only a few splitting ratios. Adding complexity, these coordinates were checked until they reached a tight range and it was therefore not necessary to take volume parameters into account. To conclude the discussion about the variables chosen to properly describe the system, it is worth mentioning how diffusive fluxes (mass and energy) among the reactors were brought into the picture. Diffusive fluxes are not explicitly treated in the optimization. The amount of mass exchanged through diffusion is reproduced as a corresponding convective flow, which is not explicitly separated from the total flow processed by the reactors [20,22,23]. Energy diffusion between two separated reactors results in a different temperature with respect to an expected value. This is considered by determining the most suitable temperatures for each zone through the RTD-fitting procedure. In conclusion, the unknown variables determined by fitting the computational model to the experimental RTD through an optimization procedure were splitting ratios and temperatures in case of reactive conditions.

The selected network, shown in the following sections, could fit both air and oxyfuel operation points, exhibiting only one global minimum. Employing the same CRN for both operating conditions supports identifying the crucial differences between air and oxy-fuel mixtures through the different values of the fitting variables. After fitting the model response against the experimental data, the network can describe the mixing features of the system and the chemical kinetics applied to the CRN. This is achieved by employing the newly developed NetSMOKE $[48,49]$ tool for the kinetic resolution of CRNs, a chemical reactor solver developed in $\mathrm{C}++$. It utilises the OpenSMOKE++ libraries for CSTRs and PFRs [50]. The CRN is regarded as a system of nonlinear equations for the mass balance of a certain species across each device. The equations are solved for every species included in the chosen chemical kinetic mechanism, which in this case is the GRI kinetic mechanism [51].

\subsection{Oxy-Fuel Combustor and Residence Time Distribution Measurements}

Figure 2 shows the geometry and dimensions of the oxy-fuel combustor (OFC). The test rig was designed to investigate gas flames and gas-assisted coal/biomass flames operating in both air and oxy-fuel conditions. This setup has been thoroughly investigated both experimentally $[46,47,52-55]$ and numerically [56,57]. The fuel employed in the referenced studies, as well as in the present one, is methane. As from Figure 2, the burner down-fires into the combustion chamber. Walls are made of wedged fused silica to enable optical access. A partially premixed mixture of fuel and oxidizer (either air or an oxyfuel mixture, details in Table 1) is injected from the inner orifice (primary flow, I). 

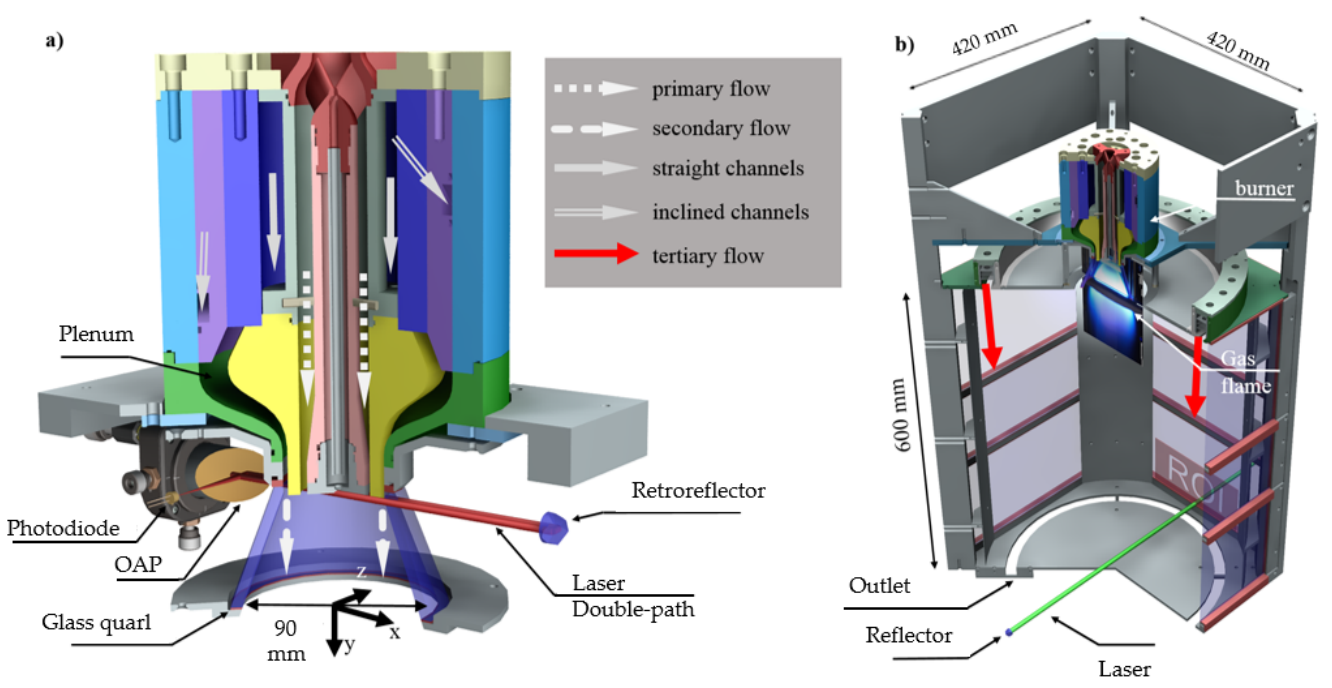

Figure 2. Sectional view of the burner with the combustion chamber and optical equipment for the RTD measurements: (a) burner and quarl flows; (b) entire combustion chamber with the depiction of gas flame. Reprinted with permission from [47] ${ }^{\circledR}$ The Optical Society.

Table 1. Details of the points of operation [52]. Data below reproduced with permission from ref. [52], 2017, Elsevier.

\begin{tabular}{ccccc}
\hline Operation Points & NRair & NR30 & Rair & R30 \\
\hline Oxidizer Air $/ \mathrm{O}_{2} / \mathrm{CO}_{2}$, vol $\%$ & $100 / 0 / 0$ & $0 / 30 / 70$ & $100 / 0 / 0$ & $0 / 30 / 70$ \\
$\mathrm{I} \mathrm{CH}_{4}, \mathrm{Nm}^{3} / \mathrm{h}$ & - & - & 2.01 & 2.01 \\
I Oxidizer, $\mathrm{Nm}^{3} / \mathrm{h}$ & 13.55 & 8.16 & 13.55 & 8.16 \\
II Straight Oxidizer, $\mathrm{Nm}^{3} / \mathrm{h}$ & 5.97 & 3.76 & 5.97 & 3.76 \\
II Inclined Oxidizer, $\mathrm{Nm}^{3} / \mathrm{h}$ & 12.02 & 7.27 & 12.02 & 7.27 \\
III Oxidizer, $\mathrm{Nm}^{3} / \mathrm{h}$ & 69.95 & 42.60 & 69.95 & 42.60 \\
Equivalence ratio $\phi, \mathrm{I}$ and II & - & - & 0.6 & 0.69 \\
Thermal Power, $\mathrm{kW}$ & - & - & 20 & 20 \\
Swirl number & 0.47 & 0.47 & 0.47 & 0.47 \\
\hline
\end{tabular}

An outer orifice comprising straight and inclined channels delivers a swirled flow of oxidizer (secondary flow, II). A tertiary flow of oxidizer is injected closer to the combustor walls (Figure 1b).

For simplicity, the cases employing air as the oxidizer are addressed as NRair/Rair, and oxy-fuel mixture cases are referred to as NR30/R30 (Table 1), where the initials NR and $R$ designate non-reactive and reactive mode.

These operating conditions are the reference for the experimental work carried out in the test rig $[52,54,55]$. As clear from Table 1 , they were also conceived so that the flames would have the same output power. This is of particular importance, as the final goal of such studies is to understand the difference between a more sustainable combustion process and a reference one, ensuring there is no performance reduction. The choice of the different volume flows for the two selected operative conditions was furthermore based on previous investigation. In [52], an oxy-flame stabilization method which relied on burner aerodynamics was applied. It was resumed in [53], where it was found that the momentum fluxes at the inlet nozzles of a combustion chamber have a decisive influence on the flame shape. Therefore, following these findings, the volumetric flow rates in Table 1 were selected to reproduce the same axial momentum fluxes as the reference flames in [52].

RTD measurements were carried out for cold and reactive conditions, investigating both oxidizing streams [46,47]. The non-reactive tracer, $\mathrm{CH}_{4}$ for isothermal measurements and $\mathrm{HCl}$ during combustion, was added through the primary flow orifice (see Figure 2) and detected in situ through direct Tunable Diode Laser Absorption Spectroscopy (TDLAS). 
The temporal evolution of the tracer concentration yielding the gas phase RTD was measured by simultaneously detecting its concentration immediately after its injection (optical equipment in Figure 2a) and before the combustor exit (optical equipment in Figure 2b). The tracer was detected 50 times for each operating condition, and the resulting RTD curves result from the average of these single-injection experiments.

\subsection{Modelling}

Following the guidelines mentioned earlier, a CRN was designed for the OFC. PIV experiments [52] support a consistent identification of the mixing zones together with the CFD-predicted flow field in Figures 3 and 4, which stems from an investigation of the suitability of LES for computing RTDs in complex combustors [56]. The joint interpretation of the RTD data and the available flow visualization material led to a first gross flow schematization, which is shown in Figure 3a.

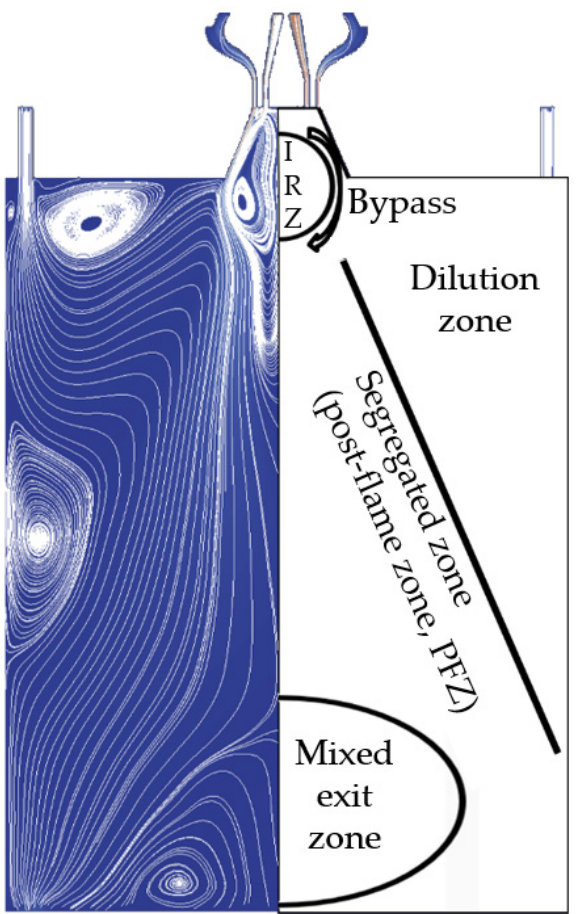

(a)

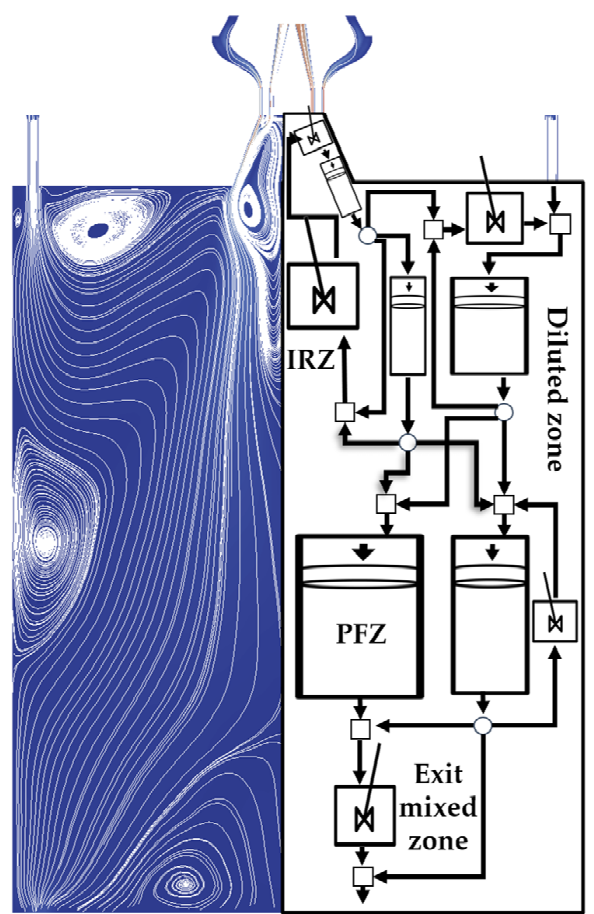

(b)

Figure 3. Streamlines extracted from CFD calculations of the mean flow field for non-reacting, air-oxidized conditions [56]. (a) gross schematization highlighting the main mixing zones is superimposed to the streamlines; (b) CRN model of the combustor.

The delivered swirled flow, typical of industrial combustion systems [58,59], exhibits the classical structure comprising a flow bypass and a central recirculation, as seen in Figure 4 . The primary and secondary flow injected from the respective orifices generate a small corner recirculation zone, also visible in Figure 4. Thus, understanding and subsequent correct schematization of the near nozzle region is essential for the accuracy of the entire CRN, especially to reproduce the reactive flow field and properties. Figure 4 shows the IRZ and the small corner recirculation zone schematized by CSTRs due to the intense mixing. The IRZ is enclosed by a high-velocity flow [52] with a clear preferential path directed toward the combustion chamber. Therefore, a series of PFRs represents this region referred to as "bypass" in Figure 3a. As shown in Figure 4b, the difference between the isothermal model and the reactive one lies in the presence of a separated reactor to schematize the flame during combustion. Swirling flows promote the stabilization of the flame in the shear layers delimiting recirculation zones. 


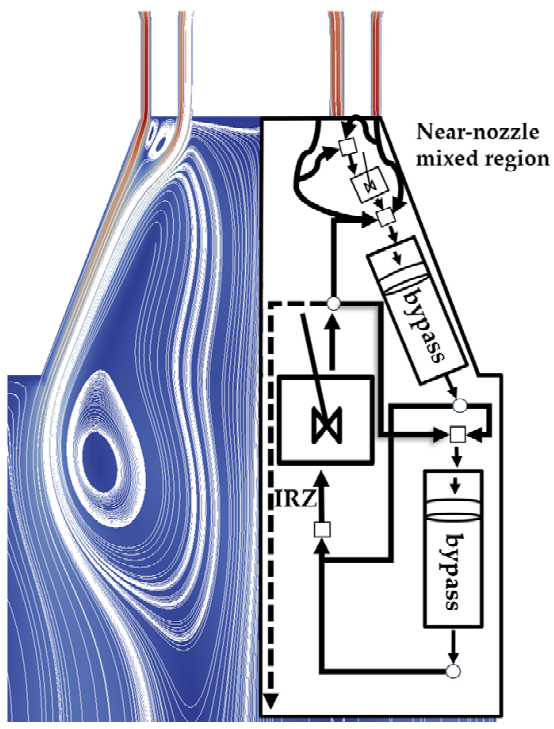

(a)

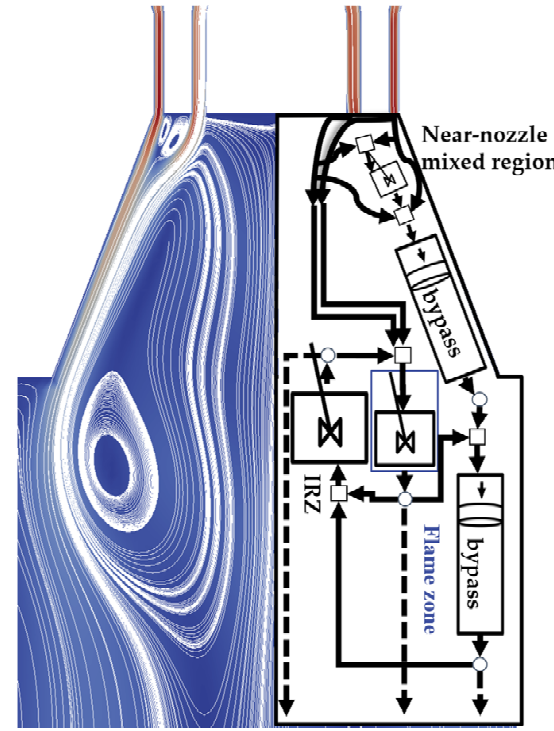

(b)

Figure 4. Magnification of the near-nozzle and CRN depiction: (a) isothermal case; (b) reactive case.

This region yields high temperatures and a fast formation rate of radical species. Thus, it would be a considerable error to fail to take this into account while dealing with a reactive case; a CSTR represents it due to the high turbulence levels and the swirl motion mixing. After the near-nozzle region in Figure 3 follows a segregated region represented by a PFR that serves as a post-flame zone (PFZ). As mentioned (see Figure 2 and Table 1), oxidizer is introduced alone in the proximity of the combustor wall. This stream defines a dilution zone, resulting in lateral recirculation zones. PFRs represent this dilution region with a recirculation CSTR to capture dead zone behaviour [60]. In the lower part of the combustor, a mixed region was also identified and represented as a CSTR. The complete model for the entire combustion chamber is depicted in Figure $3 b$.

Figure 5 shows the dynamic response of the CRN optimization against the experimental RTD. The two responses are superimposed, and the error is also reported in this plot in green. The experimental inlet pulse is displayed for completeness, although scaled to the order of the plot magnitude for graphical reasons.
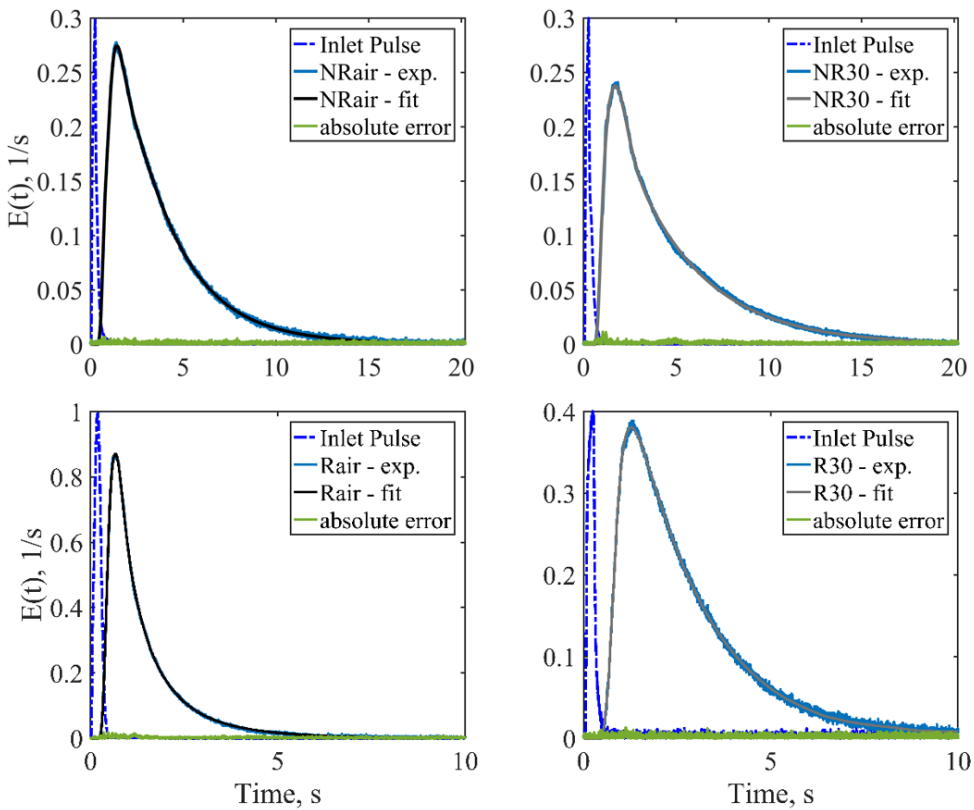

Figure 5. Experimental RTD and superimposed CRN fit for each operating condition, Table 1. 
The appropriate fit of the CRN-RTD versus the experimental one confirms the designed model capability in describing the mixing features inside the system. Nonetheless, it is still necessary to check the suitability of the network to capture the underlying reactive features adequately.

Species concentrations reported in Ref. [53] were measured $35 \mathrm{~mm}$ upstream of the exit plane of the combustor. This coordinate was identified as a specific reactor zone in the OFC, namely the mixed exit zone (see Figures 3 and 4). All of the species compared in Table 2 exhibited good agreement for the air-fired case, Rair. The agreement for R30 was suitable for all the considered species, with a slight overprediction of $\mathrm{CO}$ that impacted the $\mathrm{CO}_{2}$ mole fraction values. $\mathrm{CO}$ formation was susceptible to the flow field characteristics. It is possible that the present model, even if appropriately designed to capture the main mixing features, slightly overestimates the mixing within the dilution region. This region had a lower temperature than the main flow path, and its CO content was high because of the slower reactivity at low temperatures. If a higher share of reacting flow carrying $\mathrm{CO}$ were entrained in the cold side zone, a higher amount of $\mathrm{CO}$ would be quenched and available for mixing along the combustor coordinate. Despite this discrepancy, the model was able to describe the system's mixing features and species formation.

Table 2. Comparison between experimental data [53] and CRN-predicted species concentration near the exit of the combustor. "Exp." data reproduced with permission from ref. [53], 2018, Elsevier.

\begin{tabular}{cccc}
\hline & CRN & & Exp. \\
Rair & 1140 & $\mathrm{CO}, \mathrm{ppm}$ & 1300 \\
R30 & 107 & $\mathrm{CH}_{4}, \mathrm{ppm}$ & $\sim 40$ \\
Rair & 559 & & 570 \\
R30 & 61 & $\mathrm{O}_{2}$, mole fraction & $1.7 \times 10^{-1}$ \\
Rair & $1.6 \times 10^{-1}$ & & $2.2 \times 10^{-1}$ \\
R30 & $2.3 \times 10^{-1}$ & & $1.9 \times 10^{-2}$ \\
Rair & $1.9 \times 10^{-2}$ & $\mathrm{CO}_{2}$, mole fraction & $7.25 \times 10^{-2}$ \\
R30 & $7.1 \times 10^{-2}$ & & $3.9 \times 10^{-2}$ \\
Rair & $4 \times 10^{-2}$ & $\mathrm{H}_{2} \mathrm{O}$ mole fraction & \\
R30 & $6.2 \times 10^{-2}$ & & \\
\hline
\end{tabular}

Moreover, the model correctly reproduced the noticeable CO reduction compared to the Rair system. An important implication of these results is that the model properly predicted the different mixing and reactive properties of the flow investigated under two different oxidizing conditions. It was therefore employed in this study to understand the system behaviour when switching from air to oxy-fuel conditions.

Key parameters selected and defined to carry out this comparison are explained as:

- $\tau^{m}$, s-Mean residence time inside the system;

- $\sigma^{2}, \mathrm{~s}^{2}$-Variance of the distribution;

- $\tau^{c}, \mathrm{~s}$-Convective time delay, time before the first arrival of the tracer;

- $m_{I R Z} / m_{\text {in_quarl }}$-Mass flow entrained into the IRZ, related to the mass flow fed to the quarl;

- $m_{\text {dead }} / m_{\text {tot }}$-Total mass flow entrained into the dead volume zones, related to the total mass flow fed to the system;

- $m_{\text {flame }} / m_{\text {in_quarl }}$-Mass flow entrained into the flame zone reactor, related to the mass flow fed to the quarl (only for reactive cases);

- $m_{\text {dilution } \rightarrow \text { main }} / m_{\text {tot }}$-Mass flow entrained from the lateral dilution zone in the main (central) flow.

The standard deviation for each listed key parameter was also calculated, and is shown in Tables 3 and 4 designated as Std. This standard deviation was calculated by fitting the CRN model to the single-injection curves (as explained in Section 2.1, each experimental 
RTD curve is the average of single injections of tracer) and calculating the key parameters for each single injection fit. The same procedure was carried out for both the NRair and Rair cases.

Table 3. Selected properties of the CRN model: non-reactive case.

\begin{tabular}{cccc}
\hline Parameter & NRair & NR30 & Std. \\
\hline$\tau^{m}, \mathrm{~s}$ & 3.8 & 4.7 & \pm 0.2 \\
$\sigma^{2}, \mathrm{~s}^{2}$ & 8 & 12 & \pm 1 \\
$\tau^{c}, \mathrm{~s}$ & 0.4 & 0.7 & \pm 0.1 \\
$m_{I R Z} / m_{\text {in_quarl }}$ & 1.4 & 1.6 & \pm 0.2 \\
$m_{\text {dead }} / m_{\text {tot }}$ & 0.82 & 0.99 & \pm 0.04 \\
$m_{\text {dilution } \rightarrow \text { main }} / m_{\text {tot }}$ & 0.79 & 0.85 & \pm 0.07 \\
\hline
\end{tabular}

Table 4. Selected properties of the CRN model: reactive case.

\begin{tabular}{cccc}
\hline Parameter & Rair & R30 & Std. \\
\hline$\tau^{m}, \mathrm{~s}$ & 1.5 & 2.9 & \pm 0.2 \\
$\sigma^{2}, \mathrm{~s}^{2}$ & 1.7 & 3.8 & \pm 0.5 \\
$\tau^{\mathcal{c}}, \mathrm{s}$ & 0.25 & 0.52 & \pm 0.05 \\
$m_{I R Z} / m_{\text {in_quarl }}$ & 0.50 & 1.38 & \pm 0.09 \\
$m_{\text {dead }} / m_{\text {tot }}$ & 0.80 & 1.4 & \pm 0.05 \\
$m_{\text {dilution }} \rightarrow$ main $_{\text {tot }} / m_{\text {tot }}$ & 0.54 & 0.50 & \pm 0.09 \\
$m_{\text {flame }} / m_{\text {in_quarl }}$ & 0.4 & 0.6 & \pm 0.01 \\
\hline
\end{tabular}

\section{Results and Discussion}

The impact of oxidizers on the mixing and reactive behaviour of the combustor is discussed in the following section. The parameters introduced earlier are employed to comment on the features of systems, varying through different diluents as the system delivers the same output power. For brevity, the isothermal case is discussed first followed by results concerning the reactive cases.

\subsection{Non-Reactive Flow: Comparison between the Oxidizers}

Figure 6 shows the CRN-fits for NRair and NR30, superimposed to better highlight the differences. The onset of NR30 is delayed with respect to NRair, as can be understood from the convective time delay in Table 3. Additionally, the oxy-fuel condition causes a broader shape of the RTD. The shape of the RTD is described by the mean residence time, $\tau^{m}$, and the spread of the distribution, $\sigma^{2}$, and broader RTDs normally exhibit a higher value for these parameters.

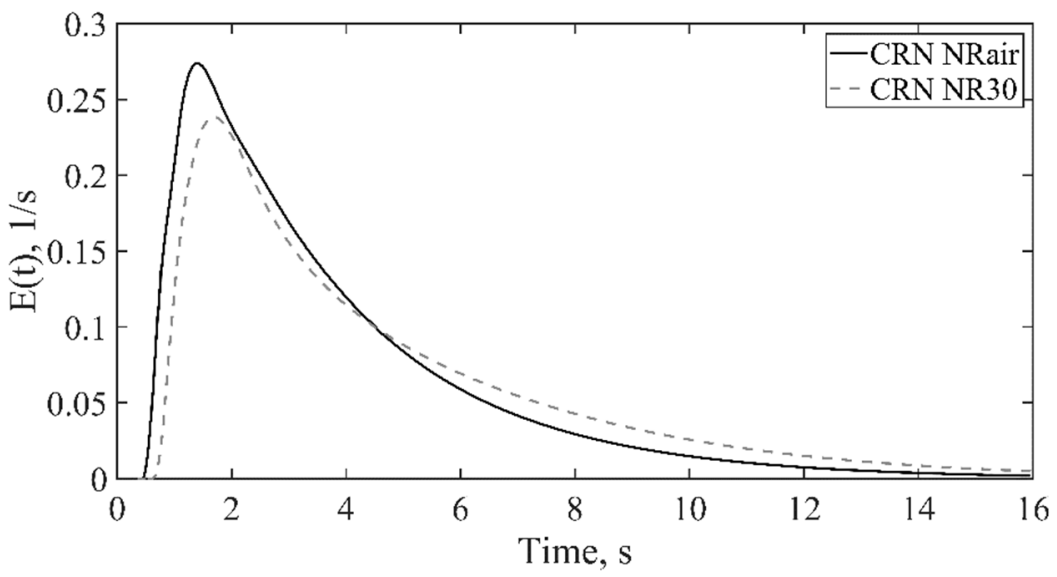

Figure 6. Comparison between the CRN-fit for NRair and NR30. 
Accordingly, in Table 3, both mentioned parameters are larger for NR30 comparing to NRair, in accordance with experimental findings [46,47]. These features agree with the lower flow rate fed to the system for NR30 with respect to NRair, as reported in Table 1. Therefore, a lower bulk velocity is associated with NR30, justifying the delayed arrival of the tracer to the detection point. This lower velocity expresses a lower impulse of the flow entering the combustion chamber, and is also responsible for a more significant share of the combustor volume associated with the IRZ, consistent with experimental evidence [52]. In this recirculation zone, more mass flow is entrained for the oxyfuel atmosphere concerning the total mass flow fed to the quarl zone, $m_{I R Z} / m_{\text {in_quarl }}$ in Table 3 , to which the lower bulk velocity is also attributed [61].

The discussion is extended with the aid of Table 3, clarifying further phenomena that contribute to the major broadening of the NR30 distribution. Under oxy-fuel conditions, a higher total mass flow is entrained in the lateral dead zones described earlier. In addition, a slightly higher percentage of mass flow from the dilution region is entrained in the main (central) flow. The dead zones in the dilution region of the combustor (see schematization in Figure 3) present the most prominent residence times in the system under the definition of dead zones [10]. As a result, the mass flow from these zones experiences a longer mixing time, and its tracer concentration is severely broadened. A higher share of this flow joins the descending bulk flow (see the factor $m_{\text {dilution } \rightarrow \text { main }} / m_{\text {tot }}$ in Table 3). These combined factors are most likely the explanation for the different broadening of the RTD curves.

\subsection{Reactive Flow: Comparison between the Oxidizers}

The RTD-fits obtained after optimizing the parameters of the reactive CRN in different operating conditions are compared in Figure 7.

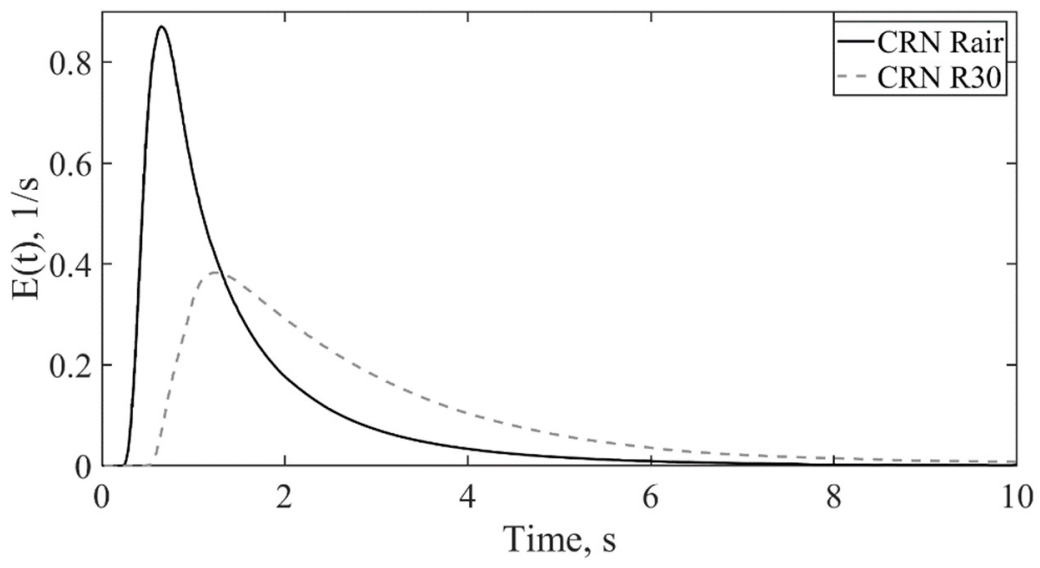

Figure 7. Comparison between the CRN-fit for Rair and R30.

Table 4 contains the values of the key parameters chosen to compare these operating conditions. What clearly emerges is the considerable difference between the spread of the two distributions and the strong resemblance between R30 and NR30 (shown in Figure 6). Referring to Figure 6, the maximum value of the distribution corresponding to NR30 is around $0.25 \mathrm{~s}^{-1}$, and that corresponding to R30 is around $0.4 \mathrm{~s}^{-1}$ (Figure 7). Instead, the two maxima corresponding to NRair (around $0.28 \mathrm{~s}^{-1}$ ) and Rair (around $0.9 \mathrm{~s}^{-1}$ ) are distant from each other, as expected when comparing a cold flow distribution to a reactive flow (higher temperatures). The broadening of the R30 distribution is characterized in Table 4 by higher $\tau^{m}$ and $\sigma^{2}$. The discrepancy between the convective time delays increases more than twofold for the oxy-fuel combustion.

For the isothermal case (see the previous section), the broader distribution calculated for R30 is partly due to the lower flow rate fed to the system compared to Rair, as explained in Section 2.1. For this reason, higher residence times are associated with oxy-fuel flows in reactive conditions. 
Besides the lower mass fed to the system, higher entrainment in recirculation zones is also calculated for R30. The parameter $m_{I R Z} / m_{\text {in_quarl }}$ in Table 4 is approximately one order of magnitude higher when feeding the $\mathrm{O}_{2} / \mathrm{CO}_{2}$ mixture as oxidizer, while the amount of mass flow entrained in the lateral recirculation zones, $m_{\text {dead }} / m_{t o t}$, is nearly doubled. Therefore, a significantly larger portion of the flow experiences intense mixing inside the system, broadening the flow distribution. The value of $m_{\text {flame }} / m_{\text {in_quarl }}$ shows a slightly higher number for R30. According to the modelling section, the flame is represented by a CSTR. Once again, a higher percentage of the flow is entrained in a mixing reactor while investigating oxyfuel combustion as compared to Rair. This phenomenon corroborates the observations about the higher mixing intensity in the oxy-fuel case. The entrainment of colder flow from the dilution region, $m_{\text {dilution } \rightarrow \text { main }} / m_{t o t}$, is quite similar for both atmospheres, being slightly lower for R30.

To further discuss the reactive system, Figure 8 shows two sample profiles inside the combustor. Species concentrations and temperatures from the CRN model are calculated over the profiles and plotted in order to compare the reactive behaviour with different oxidizers.

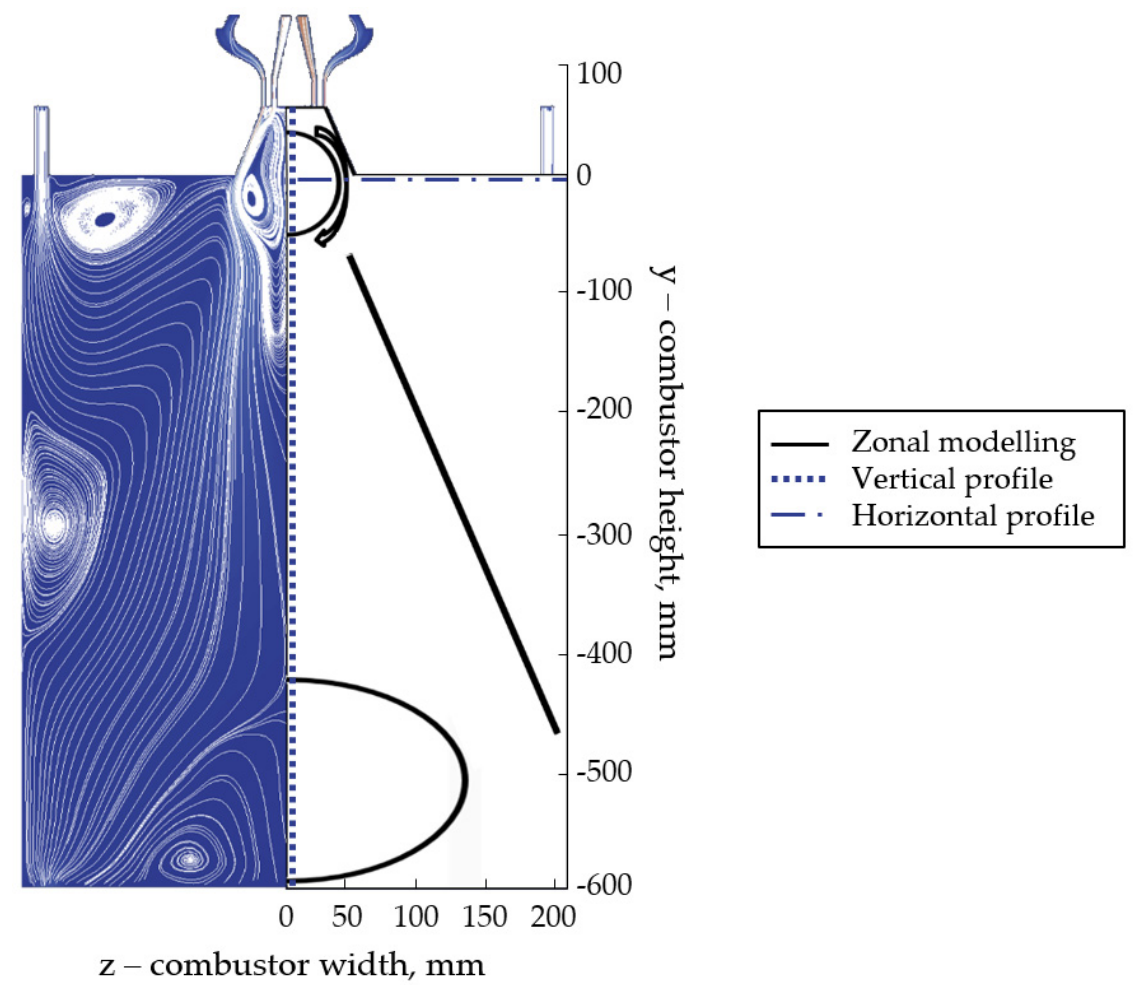

Figure 8. Sketch of the OFC and selected profiles.

Figure 9 shows the temperature trend, $\mathrm{CO}$, and $\mathrm{CH}_{4}$ concentration along the selected profiles in Figure 8. The comparison starts from the vertical temperature profile, where the first zone from the right side is the IRZ. The temperatures do not significantly differ here, being approximately $1800 \mathrm{~K}$ for both conditions. The intense mixing and high reactivity by the IRZ are apparent, as the CO values are below 500 ppm (R30 exhibits the higher value), and no methane is present in this zone (Figure 9). In the post-flame region, R30 shows a higher temperature along the whole region. The $\mathrm{CO}$ concentration shows a sharp rise for Rair due to the combined effect of direct transport of flow from the reaction regions and the side dilution region. The amount of carbon monoxide decreases until the temperatures are high enough to promote the reactions (around $1000 \mathrm{~K}$ ), and increases again as at the low temperatures diminishes $\mathrm{OH}$ formation and $\mathrm{CO}$ is no longer oxidized to $\mathrm{CO}_{2}$ through the reaction $\mathrm{CO}+\mathrm{OH}=\mathrm{CO}_{2}+\mathrm{H}$. R30 exhibits a slightly different situation, as the $\mathrm{CO}$ content experiences an increase due to transport from $\mathrm{CO}$-rich zones. However, the intensity of 
this peak is approximately one order of magnitude lower than that calculated for Rair. In other words, despite the higher $\phi$ that characterizes R30 (Table 1), the CO mole fraction in the PFZ is significantly lower during oxyfuel combustion.
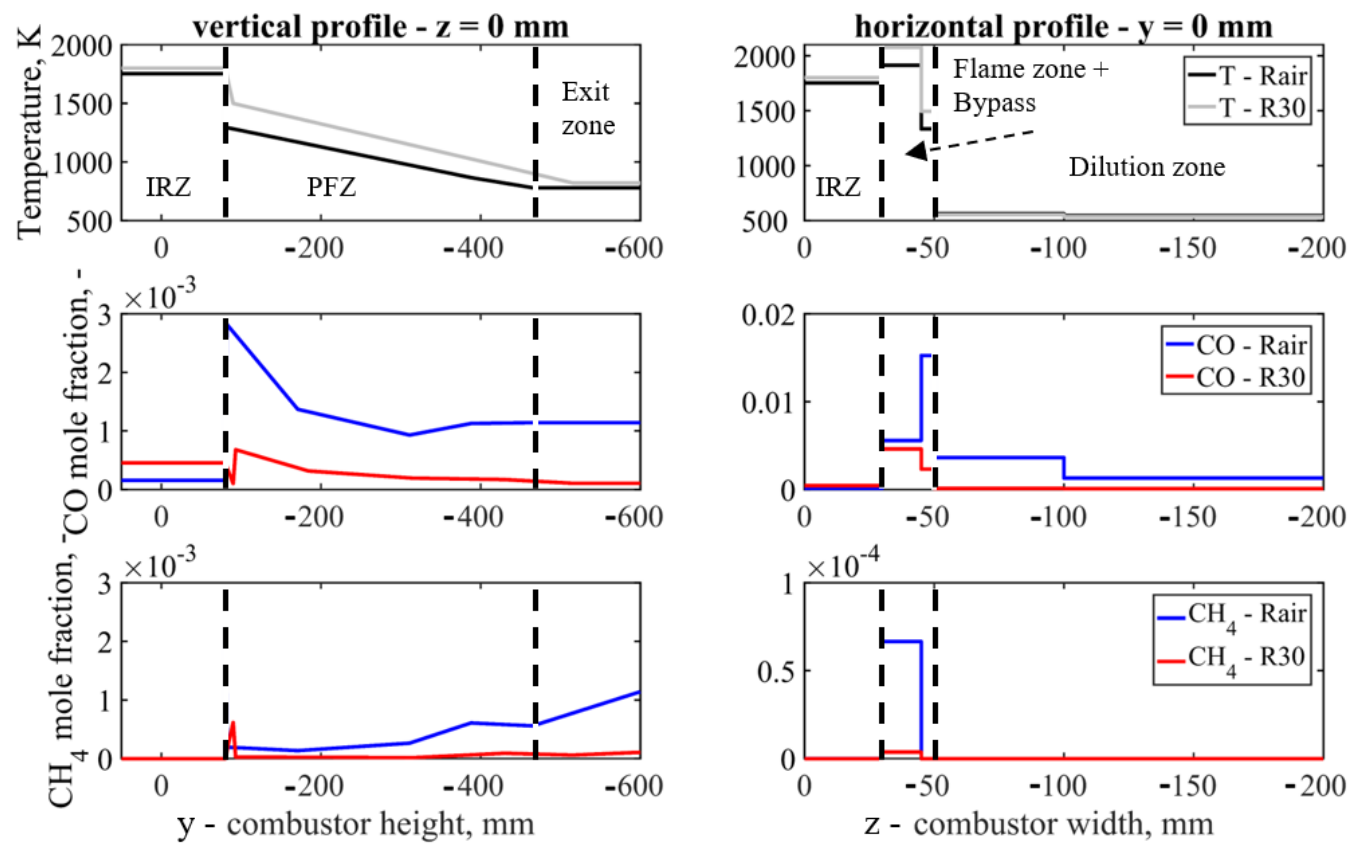

Figure 9. Impact of the oxidizer on CRN species formation and temperatures. Upper row: temperature; middle row: $\mathrm{CO}$ mole fraction; lower row: $\mathrm{CH}_{4}$ mole fraction. The $\mathrm{CRN}$ zones are highlighted.

This behavior is explained by the higher $m_{I R Z} / m_{\text {in_quarl }}$ and $m_{\text {flame }} / m_{\text {in_quarl }}$ calculated for R30 (Table 4), showing that a higher share of the inlet flow is entrained in the hightemperature IRZ-CSTR and flame-CSTR. Higher reactant consumption in these reactor zones closer to the burner region also results in less fresh fuel available to react later in the system. The entrainment of lateral dilution gas is to some extent lower for R30 $\left(m_{\text {dilution } \rightarrow \text { main }} / m_{\text {tot }}\right)$, mitigating CO mixing from colder regions and slower reactivity due to mixing cold fluid pockets in the reactive stream. In addition, the higher R30-temperatures in the PFZ also enhance $\mathrm{CO}$ reaction with $\mathrm{OH}$, promoting $\mathrm{CO}_{2}$ formation.

It is also worth mentioning that the availability of unreacted fuel near the exit of the combustor influences the different $\mathrm{CO}$ yield in the two cases. The possibility of fuel slip has also been postulated before, based on species measurements [53]. Among the model variables described in Section 2, the developed CRN model includes a flow variable that accounts for a fuel slip event which pushes flow from the quarl region to the post-flame region. Therefore, it accounts for possible unreacted methane being transported toward the exit. The value of this fuel slip variable is one order of magnitude lower for R30, meaning that the residence time in the oxy-fuel case is long enough to consume almost all feed.

This higher fuel conversion explains the diverse trend of the $\mathrm{CO}$ concentration in the different operating conditions, which is also evident from the horizontal profile. This profile cuts through the flame and bypass zones, and R30 is characterized by a higher temperature in both regions. The bypass shows a higher $\mathrm{CO}$ content for Rair, confirming that a higher amount of $\mathrm{CO}$ is transported to the post flame region. The in-flame CO content is comparable for the two investigated conditions. $\mathrm{No} \mathrm{CH}_{4}$ is calculated in the bypass region for either case. A lower reactivity in the flame reactor is found for Rair, with a significantly higher fuel content (approximately one order of magnitude higher) with respect to R30. A plausible explanation lies in the higher flame and bypass R30-temperatures, causing this mixture to achieve complete oxidation faster. Following the above discussion, and as evident from Figure 9, the oxy-fuel condition shows higher operating temperatures. This 
might at first be unexpected due to the higher specific heat of $\mathrm{CO}_{2}$ with respect to that of $\mathrm{N}_{2}$, as also shown in Table 5.

Table 5. Specific heat of the oxidizing streams [62], $\frac{c a l}{m o l ~ K}$.

\begin{tabular}{ccccc}
\hline & $\mathbf{N}_{\mathbf{2}}$ & $\mathbf{C O}_{2}$ & Air Mix. & Oxy-Fuel Mix. \\
\hline $293 \mathrm{~K}$ & 6.79 & 8.86 & 6.66 & 8.05 \\
$1500 \mathrm{~K}$ & 8 & 14.4 & 8.12 & 12.6 \\
\hline
\end{tabular}

However, according to Table 1 and Section 2.1, the two investigated operating points feature a different total flow rate. This choice is necessary to investigate the impact of the diluent on systems that deliver the same power, in line with previous studies [63,64], where burner aerodynamics were exploited to achieve successful flame stabilization. The momentum fluxes were found to play a crucial role in flame shape; thus, they have been kept equal to a reference flame in [63]. Nevertheless, the fuel flow rate is the same in both cases, determining a higher fuel-to-oxidizer ratio for R30, which also exhibits higher $\mathrm{O}_{2}$ availability with respect to Rair. These observations describe the higher oxy-fuel temperatures and its lower $\mathrm{CO}$ emission; in addition to the more efficient $\mathrm{CO}$ conversion at higher temperatures, the loss of in-flame reactivity due to entrainment of cold flow from the dilution region is expected to be lower with increased $\mathrm{O}_{2}$ availability.

\subsection{Comparison between Non-Reactive and Reactive Conditions}

For further elaboration, the different mixing behaviors and CRN-parameters of the cold and reactive systems are compared in Table 6. It appears that the key parameters for oxy-fuel mixtures are less influenced by the temperature increase due to the combustion heat release. The air flow shows the highest deviations from the cold case parameters. However, $m_{\text {dead }} / m_{\text {tot }}$ represents an exception, showing that the ratio between the mass flow entrained in the large lateral dead zones is approximately the same between reactive and non-reactive systems. It can be argued that the entrainment in the lateral recirculation zones is not influenced by combustion, as the lateral injection of oxidizer entrains and mixes with the main flow in the same manner.

Table 6. Non-reactive and reactive comparison.

\begin{tabular}{ccccc}
\hline Parameter & NRair & Rair & NR30 & R30 \\
\hline$\tau^{m}, \mathrm{~s}$ & 3.8 & 1.5 & 4.7 & 2.9 \\
$\sigma^{2}, \mathrm{~s}^{2}$ & 8 & 1.7 & 12 & 3.8 \\
$\tau^{c}, \mathrm{~s}$ & 0.4 & 0.25 & 0.7 & 0.52 \\
$m_{I R Z} / m_{\text {in_quarl }}$ & 1.4 & 0.50 & 1.6 & 1.38 \\
$m_{\text {dead }} / m_{\text {tot }}$ & 0.82 & 0.80 & 0.99 & 1.4 \\
$m_{\text {dilution } \rightarrow \text { main }} / m_{\text {tot }}$ & 0.79 & 0.54 & 0.85 & 0.50 \\
\hline
\end{tabular}

For the mentioned parameter, the difference is distinguishable under oxyfuel conditions. A higher part of the reactive flow gets trapped in the dead zones, causing a significant broadening of the reactive oxyfuel distribution (see Table 4 and Figure 7), as discussed in the previous section. The same reasoning applies to the last presented parameter, $m_{\text {dilution } \rightarrow \text { main }} / m_{\text {tot }}$.

\subsection{Comparison between Equilibrium and CRN Species Predictions}

A comparison between CRN-values and equilibrium predicted values is given in Table 7 . The equilibrium values were calculated using the hypothesis of plug flow at a constant temperature, set at $1500 \mathrm{~K}$. The results show that equilibrium CO content is more significant for $\mathrm{O}_{2} / \mathrm{CO}_{2}$ conditions $[4,24,65]$. The higher $\mathrm{CO}$ emission for air combustion compared to oxyfuel combustion is attributed to the different mixing aspects highlighted in 
previous sections. A more substantial mixing is noticed for R30, ensuring higher residence times in high-temperature mixed areas.

Table 7. Comparison between CRN and equilibrium emissions.

\begin{tabular}{lccc}
\hline & CRN & & Equilibrium \\
\hline Rair & 1140 & $\mathrm{CO}, \mathrm{ppm}$ & $2 \times 10^{-1}$ \\
R30 & 107 & $\mathrm{CH}_{4}, \mathrm{ppm}$ & 7 \\
Rair & 559 & & 0 \\
R30 & 61 & $\mathrm{O}_{2}$, mole fraction & 0 \\
Rair & $1.6 \times 10^{-1}$ & & $1.7 \times 10^{-1}$ \\
R30 & $2.3 \times 10^{-1}$ & & $2.2 \times 10^{-1}$ \\
Rair & $1.9 \times 10^{-2}$ & $\mathrm{CO}_{2}$, mole fraction & \\
R30 & $7.1 \times 10^{-2}$ & & $1.97 \times 10^{-2}$ \\
Rair & $4 \times 10^{-2}$ & $\mathrm{H}_{2} \mathrm{O}$ mole fraction & $7.1 \times 10^{-1}$ \\
R30 & $6.2 \times 10^{-2}$ & & $3.9 \times 10^{-2}$ \\
\end{tabular}

The main specie concentrations do not show a significant deviation from the equilibrium values, whereas $\mathrm{CO}$ and $\mathrm{CH}_{4}$ values deviate from those predicted by the equilibrium calculations. The reason lies mainly in the temperature non-uniformity in the combustor: as seen in Figure 9, temperatures can range from approximately $500 \mathrm{~K}$ (dilution zone) to $2000 \mathrm{~K}$ (reaction zone). The mixing of pockets of fluid with different temperatures results in loss of reactivity in the combustor, especially in the dilution zone. The resulting unreacted $\mathrm{CO}$ or $\mathrm{CH}_{4}$ amount is then entrained from the dilution region into the main flow stream. In the PFZ, it is not able to react further due to the lower temperatures. Flame quenching attributable to entrainment from the dilution region into the flame is expected to be lower with increased $\mathrm{O}_{2}$ availability, as in the case of R30. This explains the lower $\mathrm{CO}$ emission for this oxy-fuel atmosphere, as pointed out in the previous section.

\section{Conclusions}

Oxy-fuel combustion is undoubtedly a promising strategy to be coupled with CCS technologies. The employment of $\mathrm{CO}_{2}$ in the oxidizing stream determines the peculiar properties of this stream, resulting in a different flow field and temperature distribution and thus impacting the reactivity of the system. A thorough investigation of oxy-fuel combustion is crucial in order to understand this technology, and flexible modeling strategies must support the interpretation of experimental results.

Therefore, a CRN model of an intermediate-scale combustor operating under air and oxy-fuel combustion has been designed and sized against available RTD data. The relevant network parameters to be determined through the fitting procedure are the splitting ratios and the temperature for reactive conditions. The work aims at comparing oxy-fuel characteristics to reference cases, namely combustion in air. Such a comparison supports the retrofitting of existent combustors by shedding light on the crucial differences between the different operating conditions with the same delivered thermal power. The CRN model designed in this work could be properly fitted to each experimental RTD and measured for non-reactive as well as reactive flows. The reactive CRN yielded good overall agreement with experimental species, and was therefore employed to investigate the different reactive properties of oxy-fuel systems compared to air combustion.

The R30 operating conditions showed a broader RTD during cold flow measurements and modeling, explained with the aid of selected CRN-retrieved analysis parameters. The oxy-fuel atmosphere showed a higher entrainment of the seeded stream in the mixing zone, including the lateral dead zones. The more intense mixing of the tracer was even 
more pronounced for oxy-fuel during combustion. In this case, a higher share of the flow was entrained in high-temperature mixed regions. This caused a broader RTD, meaning a longer mean residence time of the flow inside the system. Further effects of the more intense mixing occurring for R30 included lower $\mathrm{CO}$ emissions and more complete fuel consumption. Overall, the effect of combustion on $\mathrm{CRN}$-derived parameters was assessed. The deviation of $\mathrm{CO}$ and $\mathrm{CH}_{4}$ from their equilibrium values was explained by the different mixing properties of the systems.

This work confirms the capability of the RTD-based CRN as an effective tool to analyze and optimize complex combustion systems, especially from a retrofitting point of view. Studies involving this strategy have typically kept their CRNs very simple, and have not previously incorporated kinetics [32-38]. As shown in this study, as well as in [49], a fairly detailed RTD-CRN which incorporates complex kinetics can shed light on the underlying phenomena in alternative combustion processes. Such a tool is therefore a valuable asset while exploring new strategies towards the sustainability of the combustion process.

Author Contributions: Conceptualization, M.A.A.; methodology, M.A.A.; software, M.A.A. and S.B.; validation, M.A.A. and S.B.; formal analysis, M.A.A., S.B. and G.B.; investigation, S.B.; resources, M.A.A., S.B., G.B., A.D., T.F. and S.W.; data curation, M.A.A. and S.B.; writing-original draft preparation, M.A.A. and G.B.; writing-review and editing, M.A.A., G.B. and A.D.; visualization, M.A.A. and G.B.; supervision, A.D., T.F. and S.W.; project administration, A.D., T.F. and S.W.; funding acquisition, A.D., T.F. and S.W. All authors have read and agreed to the published version of the manuscript.

Funding: Financial support of CRC/Transregio 129 Oxy-flame is highly appreciated (DFGProjektnummer 215035359-TRR 129). Maria Angela Agizza and Ghobad Bagheri are grateful for financial support through European Union's Horizon 2020 research and innovation program under the Marie Sklodowska-Curie grant agreement No 643134. All authors acknowledge support by the Deutsche Forschungsgemeinschaft (DFG-German Research Foundation) and the Open Access Publishing Fund of Technische Universität Darmstadt.

Conflicts of Interest: The authors declare no conflict of interest.

\section{References}

1. International Energy Agency. Energy and Air Pollution; International Energy Agency: Paris, France, 2016.

2. International Energy Agency. World Energy Outlook 2020; World Energy Outlook: Paris, France, 2020; Volume 2050.

3. International Energy Agency. Natural Gas-Fired Power; International Energy Agency: Paris, France, 2020.

4. Bagheri, G.; Ranzi, E.; Pelucchi, M.; Parente, A. Comprehensive kinetic study of combustion technologies for low environmental impact: MILD and OXY-fuel combustion of methane Comprehensive kinetic study of combustion technologies for low environmental impact: MILD and OXY-fuel combustion of methane. Combust. Flame 2019, 212, 142-155. [CrossRef]

5. Intergovernmental Pannel on Climate Change. Carbon Capture and Storage; Metz, B., Davidson, O., de Coninck, H., Loos, M., Meyer, L., Eds.; Cambridge University Press: Cambridge, UK, 2005.

6. Gibbins, J.; Chalmers, H. Carbon capture and storage. Energy Policy 2008, 36, 4317-4322. [CrossRef]

7. Pachauri, R.K.; Allen, M.R.; Barros, V.R.; Broome, J.; Cramer, W.; Christ, R.; Church, J.A.; Clarke, L.; Dahe, Q.; Dasgupta, P.; et al. Intergovernmental Panel on Climate Change. Climate Change 2014: Synthesis Report. Contribution of Working Groups I, II and III to the Fifth Assessment; IPCC: Geneva, Switzerland, 2014.

8. Abraham, B.M.; Asbury, J.G.; Lynch, E.P.; Teotia, A.P.S. Coal-Oxygen Process Provides $\mathrm{CO}_{2}$ for Enhanced Recovery. Oil Gas J. 1982, 80, 68-70.

9. Chen, L.; Yong, S.Z.; Ghoniem, A.F. Oxy-fuel combustion of pulverized coal: Characterization, fundamentals, stabilization and CFD modeling. Prog. Energy Combust. Sci. 2012, 38, 156-214. [CrossRef]

10. Nauman, E.B. Residence time theory. Ind. Eng. Chem. Res. 2008, 47, 3752-3766. [CrossRef]

11. Levenspiel, O. Chemical Reaction Engineering; John Wiley \& Sons: Hoboken, NJ, USA, 2009; ISBN 047125424X.

12. Sheoran, M.; Chandra, A.; Bhunia, H.; Bajpai, P.K.; Pant, H.J. Residence time distribution studies using radiotracers in chemical industry-A review. Chem. Eng. Commun. 2018, 205, 739-758. [CrossRef]

13. Jourdan, N.; Neveux, T.; Potier, O.; Kanniche, M.; Wicks, J.; Nopens, I.; Lq, R.D.; Zklfk, V.; Diihfw, F.; Frqwhqw, W.K.H.; et al. Compartmental Modelling in Chemical Engineering: A Critical Review. Chem. Eng. Sci. 2019, 210, 115196. [CrossRef]

14. Khodayari, H.; Ommi, F. A review on the applications of the chemical reactor network approach on the prediction of pollutant emissions. Aircr. Eng. Aerosp. Technol. 2020, 4, 551-570. [CrossRef]

15. Sturgess, G.J.; Shouse, D.T. A hybrid model for calculating lean blowouts in practical combustors. In Proceedings of the 32nd Joint Propulsion Conference and Exhibit, Lake Buena Vista, FL, USA, 1-3 July 1996; pp. 1-15. 
16. Lebedev, A.B.; Secundov, A.N.; Starik, A.M.; Titova, N.S.; Schepin, A.M. Modeling study of gas-turbine combustor emission. Proc. Combust. Inst. 2009, 32, 2941-2947. [CrossRef]

17. Bragg, S.L. Application of Reaction Rate Theory to Combustion Chamber Analysis; ADA955667; Controller HMSO: London, UK, 1953.

18. Swithenbank, J.; Poll, I.; Vincent, M.W.; Wright, D.D. Combustion design fundamentals. Symp. Combust. 1973, 14, 627-638. [CrossRef]

19. Mellor, A.M. Gas turbine engine pollution. Prog. Energy Combust. Sci. 1976, 1, 111-133. [CrossRef]

20. Andreini, A.; Facchini, B. Gas Turbines Design and Off-Design Performance Analysis With Emissions Evaluation. J. Eng. Gas Turbines Power 2004, 126, 83. [CrossRef]

21. Mendoza Orbegoso, E.M.; Romeiro, C.D.; Ferreira, S.B.; Figueira Da Silva, L.F. Emissions and Thermodynamic Performance Simulation of an Industrial Gas Turbine. J. Propuls. Power 2011, 27, 78-93. [CrossRef]

22. de Toni, A.; Hayashi, T.; Schneider, P. A reactor network model for predicting NOx emissions in an industrial natural gas burner. J. Braz. Soc. Mech. Sci. Eng. 2013, 35, 199-206. [CrossRef]

23. Broadwell, J.E.; Lutz, A.E. A turbulent jet chemical reaction model: $\mathrm{NO}(\mathrm{x})$ production in jet flames. Combust. Flame 1998, 114, 319-335. [CrossRef]

24. Timón, V.P.; Corchero, G.; Montañés, J.L. Chemical Reactor Modeling of Oxy-Fuel Combustion Chamber for Semiclosed Combined Cycle. Energy Fuels 2017, 31, 11348-11361. [CrossRef]

25. Sturgess, G.J.; Heneghan, S.P.; Vangsness, M.D.; Ballal, D.R.; Lesmerises, A.L. Lean Blowout in a Research Combustor at Simulated Low Pressures. In Proceedings of the International Gas Turbine and Aeroengine Congress and Exposition ASME, Orlando, FL, USA, 3-6 June 1991.

26. Novosselov, I.V.; Malte, P.C.; Yuan, S.; Srinivasan, R.; Lee, J.C.Y. Chemical Reactor Network Application to Emissions Prediction for Industial DLE Gas Turbine. In Proceedings of the GT2006 ASME Turbo Expo 2006: Power for Land, Sea and Air, ASME, Barcelona, Spain, 8-11 May 2006; Volume 2006, pp. 221-235.

27. Perpignan, A.A.V.; Sampat, R.; Rao, A.G. Modeling Pollutant Emissions of Flameless Combustion With a Joint CFD and Chemical Reactor Network Approach. Front. Mech. Eng. 2019, 5, 63. [CrossRef]

28. Frassoldati, A.; Frigerio, S.; Colombo, E.; Inzoli, F.; Faravelli, T. Determination of NOxemissions from strong swirling confined flames with an integrated CFD-based procedure. Chem. Eng. Sci. 2005, 60, 2851-2869. [CrossRef]

29. Stagni, A.; Cuoci, A.; Frassoldati, A.; Faravelli, T.; Ranzi, E. A fully coupled, parallel approach for the post-processing of CFD data through reactor network analysis. Comput. Chem. Eng. 2014, 60, 197-212. [CrossRef]

30. Andreini, A.; Ceccherini, A.; Facchini, B.; Turrini, F.; Vitale, I. Assessment of a set of numerical tools fot the design of aero-engines combustors: Study of a tubular test rig. In Proceedings of the ASME Turbo Expo 2009: Power for Land, Sea and Air GT2009, Orlando, FL, USA, 8-12 June 2009.

31. Innocenti, A.; Andreini, A.; Bertini, D.; Facchini, B.; Motta, M. Turbulent flow- field effects in a hybrid CFD-CRN model for the prediction of NO $x$ and CO emissions in aero-engine combustors. Fuel 2018, 215, 853-864. [CrossRef]

32. Beér, J.M.; Lee, K.B. The effect of the residence time distribution on the performance and efficiency of combustors. Symp. Combust. 1965, 10, 1187-1202. [CrossRef]

33. Van Der Lans, R.P.; Glarborg, P.; Dam-Johansen, K.; Larsen, P.S. Residence time distributions in a cold, confined swirl flow. Implications for chemical engineering combustion modelling. Chem. Eng. Sci. 1997, 52, 2743-2756. [CrossRef]

34. Ravichandran, M.; Gouldin, F.C. Residence Time Calculations Using the Numerical Simulation of Incinerator Flows. Combust. Sci. Technol. 1993, 91, 257-269. [CrossRef]

35. Bass, C.A., Jr.; Barat, R.B.; Lemieux, P.M. Identification of an ideal reactor model in a secondary combustion chamber. AIChE J. 2003, 49, 2619-2630. [CrossRef]

36. Cheng, L.; Spencer, A. Residence time measurement of an isothermal combustor flow field. Exp. Fluids 2012, 52, 647-661. [CrossRef]

37. Göckeler, K.; Terhaar, S.; Lacarelle, A.; Paschereit, C.O. Residence Time Distribution in a Swirl-Stabilized Combustor at Cold Conditions. In Proceedings of the 41st AIAA Fluid Dynamics Conference and Exhibit, Honolulu, HI, USA, 27-30 June 2011; pp. $1-13$.

38. Göckeler, K.; Terhaar, S.; Oliver Paschereit, C. Residence Time Distribution in a Swirling Flow at Nonreacting, Reacting, and Steam-Diluted Conditions. J. Eng. Gas Turbines Power 2013, 136, 041505. [CrossRef]

39. Levenspiel, O. Tracer Technology; Springer: New York, NY, USA, 2012; Volume 96, ISBN 978-1-4419-8073-1.

40. Faravelli, T.; Bua, L.; Frassoldati, A.; Antifora, A.; Tognotti, L.; Ranzi, E. A new procedure for predicting NOx emissions from furnaces. Comput. Chem. Eng. 2001, 25, 613-618. [CrossRef]

41. Kokossis, A.C.; Floudas, C.A. Optimization of Complex Reactor Networks-I. Isothermal Operation. Chem. Eng. Sci. 1990, 45, 595-614. [CrossRef]

42. Kokossis, A.C.; Floudas, C.A. Optimization of complex reactor networks-II. Nonisothermal operation. Chem. Eng. Sci. 1994, 49, 1037-1051. [CrossRef]

43. Lakshmanan, A.; Biegler, L.T. Synthesis of Chemical Reactor Networks. Ind. Eng. Chem. Res. 1996, 35, 1344-1353. [CrossRef]

44. Stephanopoulos, G. Chemical Process Control; Prentice Hall: Hoboken, NJ, USA, 1984.

45. The MathWorks Inc. MATLAB and Global Optimization Toolbox. Available online: https://www.mathworks.com/products/ global-optimization.html (accessed on 15 December 2016). 
46. Bürkle, S.; Becker, L.G.; Agizza, M.A.; Dreizler, A.; Ebert, V.; Wagner, S. In-situ measurement of residence time distributions in a turbulent oxy-fuel gas-flame combustor. Exp. Fluids 2017, 58. [CrossRef]

47. Bürkle, S.; Becker, L.G.; Agizza, M.A.; Dreizler, A.; Wagner, S. Comparison of two measurement strategies to obtain the residence time distribution in combustion chambers using tunable diode laser absorption spectroscopy. Appl. Opt. 2019, 58, 36-46. [CrossRef]

48. Mensi, M. Reactor Network Model of Biomass Combustion in Fluidized Beds. Master's Thesis, Politecnico di Milano, Milan, Italy, 2018.

49. Trespi, S.; Nicolai, H.; Debiagi, P.; Janicka, J.; Dreizler, A.; Hasse, C.; Faravelli, T. Development and Application of an Efficient Chemical Reactor Network Model for Oxy-fuel Combustion. Energy Fuels 2020. [CrossRef]

50. Cuoci, A.; Frassoldati, A.; Stagni, A.; Faravelli, T.; Ranzi, E.; Buzzi-Ferraris, G. Numerical Modeling of NO x Formation in Turbulent Flames Using a Kinetic Post-processing Technique. Energy Fuels 2013, 27, 1104-1122. [CrossRef]

51. Smith, G.P.; Golden, D.M.; Frenklach, M.; Moriarty, N.W.; Eiteneer, B.; Goldenberg, M.; Bowman, C.T.; Hanson, R.K.; Song, S.; Gardiner, W.C., Jr. Available online: http:/ / combustion.berkeley.edu/gri-mech/version30/text30.html (accessed on 15 December 2016).

52. Becker, L.G.; Kosaka, H.; Boehm, B.; Doost, S.; Knappstein, R.; Habermehl, M.; Kneer, R.; Janicka, J.; Dreizler, A. Experimental investigation of flame stabilization inside the quarl of an oxyfuel swirl burner. Fuel 2017, 201, 124-135. [CrossRef]

53. Bürkle, S.; Becker, L.G.; Dreizler, A.; Wagner, S. Experimental investigation of the fl ue gas thermochemical composition of an oxy-fuel swirl burner. Fuel 2018, 231, 61-72. [CrossRef]

54. Becker, L.G.; Von Langenthal, T.; Pielsticker, S.; Böhm, B.; Kneer, R.; Dreizler, A. Experimental investigation of particle-laden fl ows in an oxy-coal combustion chamber for non-reacting conditions. Fuel 2019, 235, 753-762. [CrossRef]

55. Becker, L.G.; Pielsticker, S.; Böhm, B.; Kneer, R.; Dreizler, A. Particle dynamics in a gas assisted coal combustion chamber using advanced laser diagnostics. Fuel 2020, 269, 117188. [CrossRef]

56. Doost, A.S.; Ries, F.; Becker, L.G.; Bürkle, S.; Wagner, S.; Ebert, V.; Dreizler, A.; di Mare, F.; Sadiki, A.; Janicka, J. Residence time calculations for complex swirling flow in a combustion chamber using large-eddy simulations. Chem. Eng. Sci. 2016, 156, 97-114. [CrossRef]

57. Knappstein, R.; Kuenne, G.; Becker, L.G.; di Mare, F.; Sadiki, A.; Dreizler, A.; Janicka, J. Large Eddy Simulation of a Novel Gas-Assisted Coal Combustion Chamber. Flow Turbul. Combust. 2018. [CrossRef]

58. Syred, N.; Beér, J.M. Combustion in Swirling Flows: A Review. Combust. Flame 1974, 23, 143-201. [CrossRef]

59. Lilley, D.G. Swirl Flows in Combustion: A Review. AIAA J. 1977, 15, 1063-1078. [CrossRef]

60. Nauman, E.B. Residence Time Distributions. Chem. React. Des. Optim. Scaleup 2008, 29, 535-574. [CrossRef]

61. Weber, R.; Dugué, J. Combustion accelerated swirling flows in high confinements. Prog. Energy Combust. Sci. 1992, 18, 349-367. [CrossRef]

62. Perry, R.H.; Green, D.W. Perry's Chemical Engineers' Handbook, 6th ed.; McGraw-Hill: New York, NY, USA, 2008.

63. Toporov, D.; Bocian, P.; Heil, P.; Kellermann, A.; Stadler, H.; Tschunko, S.; Förster, M.; Kneer, R. Detailed investigation of a pulverized fuel swirl flame in $\mathrm{CO}_{2} / \mathrm{O}_{2}$ atmosphere. Combust. Flame 2008, 155, 605-618. [CrossRef]

64. Habermehl, M.; Hees, J.; Maßmeyer, A.; Zabrodiec, D.; Hatzfeld, O.; Kneer, R. Comparison of Flame Stability Under Air and Oxy-Fuel Conditions for an Aerodynamically Stabilized Pulverized Coal Swirl Flame. J. Energy Resour. Technol. 2017, 138, 1-8. [CrossRef]

65. Bürkle, S.; Dreizler, A.; Ebert, V.; Wagner, S. Experimental comparison of a 2D laminar diffusion fl ameunder oxy-fuel and air atmosphere. Fuel 2018, 212, 302-308. [CrossRef] 